\title{
Atitudes Raciais de Pretos e Mulatos em São Paulo*
}

\author{
Tânia Mara Campos Almeida**
}

Ouvi falar da dissertação de mestrado de Virgínia Leone Bicudo, Atitudes raciais de pretos e mulatos em São Paulo (1945), pelo organizador da sua edição recente, Marcos Chor Maio (FIOCRUZ e CNPq), pouco antes de seu lançamento em novembro de 2010 - ocasião do centenário de nascimento da autora. O entusiasmo de suas palavras me levou a lhe perguntar sobre o ganho teórico e político do resgate dessa obra, no sentido de mensurar seu possível impacto no meio acadêmico e entre movimentos sociais. Ao me responder, Maio apontou vários dos seus aspectos produtivos no contexto atual, mas minha curiosidade em conhecer o material $e$ identificar esses e outros aspectos persistiu até ter em mãos um exemplar dessa edição, que possui apresentação de Rodrigo Almeida (Editora Sociologia e Política), prefácio de Elide Bastos (UNICAMP), introdução do organizador e contracapa com elogios de destacados nomes das Ciências Sociais e Psicanálise.

Apresento nesta resenha, portanto, respostas à minha pergunta. De saída, ressalto ensinamentos de Virgínia Bicudo que poderiam ser transpostos para o esclarecimento de que minhas considerações resultam do diálogo com comentários anteriores, bem como da minha trajetória pessoal e de cientista social. Minha

\footnotetext{
* Resenha de Bicudo, Virgínia Leone. Atitudes Raciais de Pretos e Mulatos em São Paulo. Edição organizada por Marcos Chor Maio. São Paulo, Editora Sociologia e Política, 2010. Recebida para publicação em março de 2011, aceita em abril de 2011.

** Professora do Departamento de Sociologia - UnB. taniamaraca@unb.br
} 
leitura está atravessada por outras interpretações $e$ a elas concatenada. Em paralelo, nota-se a construção do objeto da dissertação (atitudes de indivíduos de cor referentes ao preto, mulato e branco em São Paulo), entretecida no cruzamento de tradições disciplinares, dimensões subjetiva e social do fenômeno, relações intra e intergrupos, articulação entre raça e classe, grupos distintos de dados, enfim, no esforço constante de triangulação teórico-metodológica.

Por intermédio das argumentações de Bicudo, faz-se presente o pensamento de Park (1931) sobre conflito cultural e formação da identidade, numa junção entre Antropologia, Sociologia e Psicologia Social pela Escola de Chicago. A ele se vinculam Stonequist (1937), com atenção voltada para pessoas divididas entre diferentes mundos sociais, Faris (1937), com interesse por atitudes sociais, Pierson (1942), com tese orientada por Park e que, por sua vez, orientou Oracy Nogueira e Virgínia Bicudo. Ambos, colegas de turma, inspiraram-se mutuamente e tiveram grande afinidade no tratamento da questão racial, chegando a resultados distintos de Pierson. Enquanto este privilegiava o preconceito de classe, aqueles afirmavam que a ascensão social não apagava as distâncias das marcas de cor.

Também, por meio da dissertação falam negros e pardos de bairros populares e médios paulistanos, pertencentes à classe social denominada inferior (trabalhadoras domésticas, serventes, motoristas e operários, analfabetos ou com curso primário) e à classe intermediária (profissionais liberais e funcionários públicos, com, no mínimo, o secundário). Esse conjunto de depoimentos, organizados por grupos de cor em interseção com classe, constitui parte do material empírico da investigação. Além dele, são encontrados relatos de ex-militantes da Frente Negra Brasileira, organização política da década de 1930, bem como textos do seu jornal Voz da Raça.

Por fim, de modo indireto, comparecem no estudo pessoas de "não cor". O reconhecimento de que o sentimento de inferioridade dos pretos e mulatos advém das atitudes dos 
brancos, trazendo-os para suas conclusões, ainda que não os tenha entrevistado, mostra como Bicudo atentava-se à dimensão dialógica e de conflito embutida nos discursos dos/as entrevistados/as e na posição de subalternidade que ocupavam no quadro geral das relações raciais. Assim, ela anuncia a importância de se retirar o problema da marginalidade desses grupos de si mesmos.

Se conseguíamos definir os mecanismos psicológicos pelos quais os indivíduos se ajustavam, éramos forçados a depreender em função de que condições se estabeleciam. Parece-nos legítima a possibilidade de conhecerem-se até certo ponto as atitudes raciais de um grupo étnico, através das reações de outro grupo com o qual interaja. Fomos, pois, conduzidos a formular hipóteses sobre as imposições sociais decorrentes da estrutura social, o que equivale a dizer que também procuramos nas atitudes de pretos $e$ mulatos o reflexo da atitude dos brancos (Bicudo, 2010:157).

A sensibilidade na escolha desse tema de pesquisa, que foi pioneiro dentre as dissertações de universidades brasileiras sobre a questão racial, e a competência em lhe oferecer complexo tratamento empírico e analítico só foram possíveis a partir do lugar existencial de Bicudo. Segundo o organizador da obra, ela era uma mulher parda paulistana. Filha de mãe imigrante italiana pobre, com negro possuidor de educação secundária e do desejo frustrado, por preconceito racial, de tornar-se médico, terminando a vida como funcionário dos Correios. Seu pai era afilhado de fazendeiro, senador e fundador do jornal O Estado de São Paulo, de quem herdou o sobrenome Bicudo. Virgínia formou-se normalista e fez o curso de educadores sanitários, sendo contratada pelo Serviço Escolar do Departamento de Educação. Em 1936, iniciou a graduação em Ciências Políticas e Sociais da Escola Livre de Sociologia e Política (ELSP) - instituição vinculada à USP à época. Por ocasião do bacharelado conheceu Durval Marcondes, médico e psicanalista, que implantou o Serviço de 
Atitudes Raciais de Pretos e Mulatos em São Paulo

Higiene Mental Escolar estadual em 1938, quando Bicudo tornouse visitadora psiquiátrica. Nos anos 40 , começou a ministrar as disciplinas Higiene Mental e Psicanálise na ELSP e ingressou na sua primeira turma de mestrado. Assim, iniciou uma carreira de protagonista no campo da Saúde, Ciências Sociais e Psicanálise. Seu percurso foi peculiar e grandioso face aos resultados de sua própria pesquisa, os quais mostram a discriminação ceifadora da mobilidade social e realização pessoal.

Quanto mais subimos nas classes sociais, tanto mais aumenta a consciência de cor e tanto maior o esforço despendido para compensar o sentimento de inferioridade. Ao mesmo tempo em que se empenham em desenvolver valores pessoais, para eliminar a concepção desfavorável, procuram a autoafirmação na conquista da aceitação incondicional por parte do branco. Consequentemente resulta uma luta por status social mais árdua, dadas as barreiras das distâncias sociais na linha de cor. (...) obtêm ascensão social os indivíduos de cor dotados de inteligência $e$ que desde a infância tiveram estímulos sociais nos contatos primários com brancos. Entretanto, a ascensão ocupacional não confere ao preto o mesmo status social do branco, consideradas as restrições demarcadas na linha de cor, ao passo que o mulato garante sua inclusão no grupo dominante, embora em sua personalidade permaneçam as conseqüências do conflito mental (Bicudo, 2010:160).

A revelação clara de sua "consciência de cor", expressão empregada por Virgínia para designar o grau de discernimento dos sujeitos em relação à participação de suas características afrodescendentes nas interações, circuitos sociais e conflitos psíquicos, encontra-se no seu trabalho e nas motivações para desenvolvê-lo. Nas primeiras páginas, ela afirma ter estado atenta ao elo com os/as entrevistados/as. Quanto a si, procurou estar ciente das questões pessoais que lhe conduziram à investigação, bem como das suas atitudes sobre o objeto para que tivesse autocrítica, limitando suas projeções nas entrevistas $e$ análises. 
Quanto aos sujeitos abordados, procurou estabelecer condições psicoafetivas favoráveis à livre expressão. Esse cuidado com os processos de transferência e contratransferência, tendo em conta sua consciência de cor e da posição de autoridade profissional diante dos sujeitos interpelados, sugere influência psicanalítica no entendimento sobre a formação do vínculo e aguçado tato para lidar com fenômeno tão íntimo. Porém, ter criado um ambiente favorável à expressão não se deveu apenas ao domínio de técnicas de abordagem, como também profunda empatia com o outro. Além disso, a explicitação desse cuidado sugere a necessidade em defender-se, de antemão, de acusações de falta de objetividade e neutralidade científicas sob o crivo avaliador positivista.

Sua trajetória pessoal seria facilmente incorporada aos casos da dissertação, enquanto mulher mulata, pertencente aos estratos da classe social baixa na infância $e$ em ascensão à classe intermediária na idade adulta. Ela quebrou barreiras raciais $e$ sociais em diversos momentos da vida e encontrou no exercício intelectual um caminho para elaborar suas experiências traumáticas. Maio (2010a, 2010b) relata que Virgínia mencionou o sofrimento como um motivo de sua opção pelas Ciências Sociais na ELSP, uma vez que lá se estudava o problema do negro e se acolhia estudantes não elitistas. Esperava descobrir causas e meios de lidar com sua dor, que compreendia como originada nos intercursos sócio-culturais. Há registros em que diz ter sido vista ofensivamente como negrinha pobre quando pequena e, após ter crescido, como mulher emancipada - haja vista que era a única mulher na primeira turma de Sociologia e Política da ELSP, em 1938. Seu processo de branqueamento foi notório. Seus traços afrodescendentes foram minimizados desde as mudanças sócioeconômicas do pai, passando pela sua instrução e ocupação, até sua aparência. Seu sofrimento deslocou-se da cor e centrou-se na condição de mulher inadequada a espaços físicos e simbólicos.

O que se poderia denominar de "consciência de gênero" de Bicudo, nos parâmetros da "consciência de cor", não aparece 
formulado em seu estudo. A condição de gênero não foi problematizada, nem em relação a si nem em relação às mulheres entrevistadas. Essas aparecem em número de 17, frente a 31 casos expostos. São majoritariamente negras e mulatas das classes sociais inferiores, enquanto os homens se concentram nas classes intermediárias. Tal distribuição dos/as entrevistados/as confirma os antecedentes históricos da atual presença de negras e pardas nas camadas mais pobres e de menor escolaridade do país. Enquanto as mulheres enunciam curtas respostas à pesquisadora, homens se estendem em longas reflexões, reafirmando também a tradição patriarcal de que eles detêm a palavra. Esse cruzamento de classe, raça e gênero não fez parte dos objetivos da autora, nem foi sinalizado. Contudo, algumas pontuações a respeito podem ser feitas.

Primeiramente, Bicudo identificou a preferência de negros e mulatos de se casarem com mulheres cujos traços fossem mais claros que os seus. Em contraposição, as negras e mulatas casavam-se com consortes da mesma cor ou mais escuros, para não sentirem rejeição ou, entre as pardas, não serem chamadas de "negras" pelo marido ou suas famílias. Contudo, com pouquíssima viabilidade, várias dessas desejavam os brancos. A dinâmica matrimonial aponta para tramas veladas da discriminação, uma vez que os homens subalternos, para se identificarem, se aliarem imaginariamente com os dominantes $e$ ascenderem na hierarquia social, reeditavam com as afrodescententes a relação de poder a que eram submetidos. Logo, essas mulheres estavam (e ainda estão) em situação pior que a dos homens de cor e das brancas, fadadas a amargar as mais baixas posições numa estrutura social que conjuga racismo com sexismo.

Em segundo lugar, ressalta-se que seis dos sete casos dos negros de classe inferior são mulheres, face à totalidade de homens nos casos dos negros intermediários. Atravessa os grupos uma forte questão de gênero. A análise de Bicudo indica maior simpatia do primeiro grupo, o das mulheres, aos brancos, já que 
se viam tratadas melhor por estes que pelos negros $e$ mulatos. Essas atitudes se fundamentariam no sentimento de inferioridade do grupo. Ao perceberem os contatos com brancos mais harmoniosos, as negras responderiam a um mecanismo de evitação do conflito com eles, compensando a subalternidade e acabando por ter baixa consciência de cor.

Ao se introduzir a questão de gênero, pode-se supor outras chaves interpretativas, relativizando a auto-rejeição associada a esse grupo, a qual seria a mais alta dos grupos estudados. Ou seja, elas possuiriam conflitos com negros e mulatos por vivenciarem realmente violenta discriminação advinda deles, uma vez que representariam a alteridade de dentro, aquela parte de si mesmos por eles abominada. Só que é com elas que partilhariam relações comunitárias e sobre a inferiorização delas é que galgariam degraus na escalada do poder. Já, para os brancos, as negras pobres representariam uma alteridade distante, menos ameaçadora, fora da possibilidade de interações afetivas e sociais próximas, o que lhes proporcionaria contatos amenos.

As discussões sociológicas dos anos 1940 mal concebiam a diferença de cor fundadora da desigualdade social (o que acentua o mérito de Bicudo em tratar do assunto), muito menos vislumbravam a inclusão da diferença sexual na pauta. Apenas no fim da década, intelectuais e feministas problematizaram sistematicamente tais questões e criticaram as teorias vigentes nos meios acadêmicos. Estas eram psicanalíticas e, obviamente, Bicudo as conhecia. Grosso modo, dizia-se que o psiquismo, atrelado ao corpo feminino, talhava as mulheres à maternidade, às atividades domésticas e pouco intelectuais, bem como lhes imputava a auto-desvalorização e vitimização. Interessante como Bicudo não se rendeu a argumentos dessa natureza para explicar as atitudes das negras de classe inferior, generalizando o grupo para ambos os gêneros. Qualquer determinismo, psíquico ou biológico, na análise dos dados lhes retiraria o peso sócio-cultural, impossibilitando reflexões psicossociais ao dilema racial. 
Ao se jogar luz sobre a condição de gênero de Bicudo, juntamente com os resultados de sua pesquisa, nota-se que sua audácia era enorme e que, provavelmente, corria risco constante de ser desautorizada. Afinal, a academia se erigiu em base androcêntrica, branca e européia/norte-americana. Como ela poderia trazer à tona sua identidade de gênero nos loci da produção de conhecimento, onde se excluíam mulheres $e$ afrodescendentes? Onde ideias eram pensadas por sujeitos considerados sem história, sem classe ou qualquer marca social, assim como ideias eram tidas fidedignas da realidade e, não, formuladas a partir de pontos de vista? Provavelmente, sua consciência de gênero (somada à de cor) a levou a estratégias de acomodação frente à discriminação. Expor-se mulher ou tratar dessa questão colocaria a perder o árduo trabalho que já se mostrava à margem das referências intelectuais da época.

Talvez por ter rompido com o mito da democracia racial, que concebia equilíbrio social entre as raças formadoras do povo brasileiro, bem como com as proposições sobre o preconceito de cor estar subsumido ao de classe, seu estudo tenha tido circulação restrita. Suas considerações, embora exploratórias e passíveis de revisões, anteciparam interpretações sobre relações raciais no país nas décadas seguintes e ficaram silenciadas em período mais recente. Hoje, seu resgate contribui para se refazer a história das Ciências Sociais, do pensamento social e das mulheres afrodescendentes no Brasil. A recente reedição de sua dissertação, portanto, é louvável diante do grande valor do seu conteúdo e de sua autora.

\section{Referências bibliográficas}

Bicudo, Virgínia L. Atitudes raciais de pretos e mulatos em São Paulo.

Edição organizada por MAIO, Marcos C. São Paulo, Sociologia e Política, 2010.

FARIS, Ellsworth. The Nature of Human Nature, and other Essays in Social Psycology. New York, McGraw-Hill, 1957. 
MAIO, Marcos C. A contribuição de Virgínia Leone Bicudo aos estudos sobre as relações raciais no Brasil. In: BICUDO, Virgínia L. Atitudes raciais de pretos e mulatos em São Paulo. São Paulo, Sociologia e Política, 2010a, pp.23-60.

Educação sanitária, estudos de atitudes raciais e psicanálise na trajetória de Virgínia Leone Bicudo. Cadernos Pagu (35), Campinas-SP, Núcleo de Estudos de Gênero-Pagu/Unicamp, 2010, pp.309-355.

PARK, Robert. Human Nature, Atitudes, and the Mores. In: YounG, K. (ed.) Social Atitudes. New York, Henry Holt \& Co., 1931, pp.17-45.

PIERSON, Donald. Negroes in Brasil: a study of race contact at Bahia. Chicago, University of Chicago Press, 1942.

STONEQUIST, Everett. The Marginal Man: a study in personality and culture conflict. New York, Charles Scribner's Sons, 1957. 